\title{
Individualize, Ignite, and Inspire (I-I-I-Model) The Way To Achieve Organizational Excellence......
}

\author{
${ }^{1}$ M. Madhusudhana Rao, ${ }^{2}$ Dr. Sukumar Puhan \\ ${ }^{I}$ Research Scholar, Department of Business Management, CMJ University, Shillong, India. \\ ${ }^{2}$ Professor, Department of Mechanical Engineering, GKM College of Engineering \& Technology, Chennai.
}

\begin{abstract}
Organizational Excellence is an aspect, which cannot be measured by tangible numbers in any Organization. All that gets measured is the efficiency and effectiveness of the various activities that the Organizations execute \& perform day-in and day-out. But truth lies in the fact that measurement systems can bring the Business results and make organization as the leader in the respective industry. An Excellent Organization has to strive beyond the Business Excellence. All the very exciting components called Best place to work, Place of positive social change and uplifting the human spirit and the influence all these elements should be felt for many generations.

Organizational Excellence is continuous improvement journey. A comprehensive and effective way for the organizations to excel beyond Business, Business for life time is to Individualize, Inspire and Ignite -The I-I-Imodel of Organizational Excellence!
\end{abstract}

Keywords: Organizational Excellence, Business, Individualize, Inspire and Ignite

\section{Introduction}

There are several well-known approaches to seemingly impossible dream to achieve Excellent Organization. All efforts are made to bring out this paper after referring the vast literature that is available already and every attempt is made to provide a holistic approach for journey of Organizational Excellence through "Individualize, Inspire and Ignite, the way to achieve Organizational Excellence.(III approach)". This paper will discuss how Organizational Excellence is the key to success even during tough times; and also due to various economic \& political and geographical conditions. It's not all about only Business excellence, it is about sound business principles, team work, passion, Influence on the society and beyond. Also Some of the key information are quoted below.

The Lean principles and the Toyota Way (Liker, 2004; Liker \& Hoseus, 2008; Liker \& Meier, 2007; Womack \& Jones, 2003) offer promising pathways.

There are well known books published on Organizational excellence and gave the clear way to achieve it using the 5 pillars of Organizational Excellence by H. James Harrington, CEO of the Harrington Institute Inc. and chairman of the board of Harrington Group published by Parton press throughout 2006. The article gave all the 5 pillars are 1.Process Management 2.Project Management 3.Change Management 4.Knowledge Management and 5.Resource Management.

Also, Fortna inc., a well known company in the supply chain Management published a white paper and provided "Seven Keys to Organizational Excellence" and identified the Seven Keys are 1.Organization Development and readiness 2.Lean Processes 3.Training and Cross-training 4.labour management software 5.Labour standards 6.Leadership skills and 7.Motivation.

David Koichi Chao, President of Lean Sensei International, made a bold and visionary statement in his book 'Lean Reflections' (2009): "I believe in the power of lean to transform the world in a way we cannot begin to imagine". Mr. Chao went on to say that the lean principles involve three things: Changing people to improve teamwork, changing the process to reduce waste, and changing the mindset to enhance the culture. Thus, transformation of people is the first step towards transforming the organization and culture. The positive psychology movement (Crabtree, 2004 a, b; Linley, Harrington, \& Page, in press) offers another promising approach. Positive affects (Fredrickson, 2009; Lord, Klimoski, \& Kanfer, 2002), psychological capital (Luthans, F., Luthans, K. W., \& Luthans, B. C., 2004), and signature strengths (Hodges \& Clifton, 2004; Peterson \& Seligman, 2004) are all shown to be linked to job satisfaction and productivity. Some companies attempt to establish internal staff resources aimed at supporting organization design initiatives. There is a substantial body of literature in the field, arguably starting with the work of Peter Drucker in his examination of General Motors decades ago. Other key thinkers built on Drucker's thinking, including Galbraith (1973), Nadler, et al. (1992) and Lawrence \& Lorsch (1967). 


\section{Organizational Excellence}

If we consider the Global efforts towards helping the Organizations for achieving their Business excellence, Operational excellence, Sustainability, HR excellence etc, most of the countries are encouraging various excellence models and propagating for the organizations to adopt them to reap the benefits sustainably improving business and also bringing the aspect of corporate social responsibility for the wellbeing of society and also uplifting the human spirit. There is no scope of doubt in any corner for the efforts that global industry, Industrial experts, Management gurus, and various stake holders are striving to achieve the excellence in every activity. Honestly, an exponential growth has been achieved in the business front and also in various operations. Various Excellence models like EFQM, Malcolm Baldridge, The Australian Model, BPIR, Canadian Framework etc., give key elements or the components of the Excellence journey for any organization. The following are 10 most important criterions advocated in these models all-encompassing the Excellence framework.

1. Leadership

2. Policy \& Strategy

3. People

4. Process

5. Systems \& Technology

6. Partnerships

7. Customer Centricity \& markets

8. Knowledge Management

9. Innovation

10. Society

Organizations in the journey to excellence, are implementing the criterions mentioned above and trying to excel in their own ways. But if we review the findings or analyze the statistics for the scores of various assessments that have been done so far in the world using any model, or any company of any size, the results exhibit a wide gap that exist in the organization.

The Major gaps identified can be categorized under the following sections :

1. Leadership to Strategy

2. Strategy to Operations or Execution

3. Strategy to Systems /processes/Partners

4. Execution to Results

5. Results to Leadership

6. Results to People \& Society.

In a Holistic approach of any of these models applied or implemented in any of the organizations, results reveals that there is a sure gap of more than $30 \%$ in any of the criteria's compared to the maximum score for that each criteria. Even if we try to observe any of the organizations assessment scores of maturity of the criteria's, there will be always high level of inconsistency among each of the criteria's. These gaps are universal irrespective of Excellence model or type of organization (any domain or any size). And this is the real problem or the problem of the day. Hence there is a need to relook at the way that we are adopting the excellence models or the models itself. Further to this, deep studies in to various models implementation and current assessment reports of various companies, it is found that the way that we are implementing the models itself needs a different thought process and also need to deep dive in to fundamentals of creating the organizational culture, creating the work culture, motivation, belongingness, organizational bonding ,customer focus etc are not given enough priority or needs redefining appropriately.

Currently most of the matured organizations are using the organization excellence journey in a Top down approach which means that the leadership is driving the strategy of the organization \& operations are percolating down to employee level. So all the key components of the excellence journey right from inspiring leadership is useful to ignite the various systems \& Creating a passion at individual level .

Though the conventional model is providing benefits upto the extent of $60 \%-70 \%$ of the targeted results of the organization excellence components, the gap of 30\%-40\% still remains because of the fact of the leadership driving the excellence journey \& not the ownership by every individual of the organization. Hence the total ' $U$ " turn of the approach itself from INDIVIDUALS to LEADERSHIP will help as the Game changer.

This Bottom -Up approach of achieving Organizational excellence focusing on the Individuals to Ignite the various systems and there by inspiring the leadership which is referred as Individualize , Ignite , Inspire ,I-I-I model of Organizational Excellence. 
Individualize, Ignite, Inspire (I-I-I-model) The way to achieve organizational excellence.......

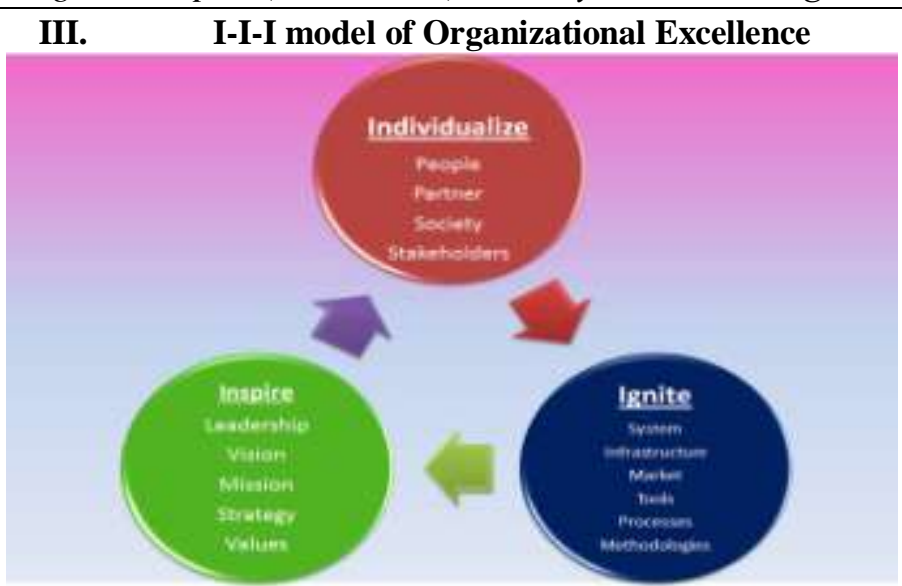

Fig 1: I-I-I model (Individualize, Ignite, Inspire)-Proposed Model for Organizational Excellence.

The proposed '3I-Model' tries to attempt to bring the approach for Organizational excellence in a much robust way and bridges the gap of current approaches of Organizational excellence journey. After having elaborate studies on the various OE models having detailed discussions with various stakeholders of the OE fraternity \& also by looking at the various results that are available in the benchmarking forms like the GEM Counsel, Baldridge Model, EFQM model, Australian Excellence model, Canadian model \& other significant models in the globe, it is found that if the individuals feel \& take the ownership \& develop belongingness of the excellence journey so that each INDIVIDUAL or group of individuals who have a Major stake in the organization, will IGNITE, the various systems .processes of the organizations through the Innovation, continuous improvements, will lead to INSIPIRNG the whole strategy, operational excellence of the organization which will lead the leadership to act upon the Organization Excellence.

In this scenario, the ownership is at every individual level who will act as a inspired leader himself .so it is totally a game change where the leadership provides the collaborative atmosphere to every individual \& get a collective ownership for bringing the organization at its best, stating simply ....the Bottom up approach ... . This concept of the individuals, ignited with passion. Leading the way to organizational Excellence was expressed by every management guru of the world time \& again. But ironically, the same was not implemented while adopting the $\mathrm{OE}$ model in the organizations

The Critical success factor for the success of the OE model is the change in the mindset of the individuals from identifying the WIIFMs ( What is in it for Me ) to identifying the opportunity of contributing to the growth of the organization (How do I contribute to the Organization) ....

This metamorphic behavior can be achieved only by the proposed 3I's model,

Let us take a deeper look into each of the 'I's ......

\subsection{Individualize}

The individuals who are the key stake holders to the organization growth should be able to contribute to the organizational excellence. So there are four types of individuals who are part of the organization excellence journey i.e., 1. Employees, 2. Partners 3. Stakeholders 4. Society. Let us look into how each of these individuals can contribute to organization excellence.

\subsubsection{Employees:}

Today in most of the organizations the majority of the employees are becoming the operational execution people who have been given the objectives or the key result areas (KRAs) . These KRAs are coming from the strategy, vision, mission of the organization, Which means that the employees are meant only to execute \& not be a part and parcel of making the strategy and vision of the organization.

Hence there is a need of bringing ownership to the employees (majority of the Org.) to involve in strategy making and formulating the vision of the organization. This is simply the bottom-up approach than the existing top-down approach. Now the real question is how can this be achieved by the organizations .In the current scenario there are no methods devised for doing bottom-up approach. The below one will give a proposed steps for achieving bottom-up approach.

1. Making all the employees to understand the business purpose and the scope of the business of the organization.

2. Providing an opportunity for all the employees to involve in the Vision/Mission exercise.

3. Making every employee to involve and contribute to the strategic planning of the organization.

4. To enable to share the growth, profits, and loss of the organization to each and every employee in the same manner (equal business ownership) . 
Individualize, Ignite, Inspire (I-I-I-model) The way to achieve organizational excellence......

5. Leadership to enable all the required infrastructure, mentorship, etc., to the employees to ignite them for achieving the Vision of the organization.

\subsubsection{Partners:}

Partners in the organization have a very significant role and also business critical role. Today in most of the organizations the relationship between the organization and the partners is more of win -win business. Though this is giving some benefitable results but still the partners are not in a position to see the organizations growth irrespective other wins. So the organizations responsibility to bring such kind of bonding to the partners and making them the realistic owners to help the organization to meet their strategic objectives and vision of the organization.

\subsubsection{Stakeholders:}

All the relevant stakeholders are an integral part of the organizational success. So in the journey of organizational excellence the leadership of the organization is to ensure that the every stake holder should shoulder the responsibility of the organization's Vision/Mission/Strategy.Stakeholders responsibility is not only providing the inputs that are required but also to enable the business growth, sharing the problems of the organization. The sense of belongingness to the stakeholders is very much important to play a critical role in the organizations growt

\subsubsection{Society:}

If we consider the societal part of Indian organizations is very minimal, though the Indian corporate sector is striving to do a lot in terms of their corporate social responsibility there is a school of thought that the word corporate social responsibility is wrongly coined, implemented and the purpose of making society as a part of organization is not achieved. Today in most of the organizations corporate social responsibility is seen as a charity work that can be done to some small section of the society which is nearby. But the real sense of corporate social responsibility is much different, it is to make the society be a part of your organizational growth and make society to feel that this organization is important to the society itself. So the organizations has to do many activities which will improve the society as a whole and which will uplift the standards of the society. By means of this the organization should provide the ownership and sense of belongingness to the society.

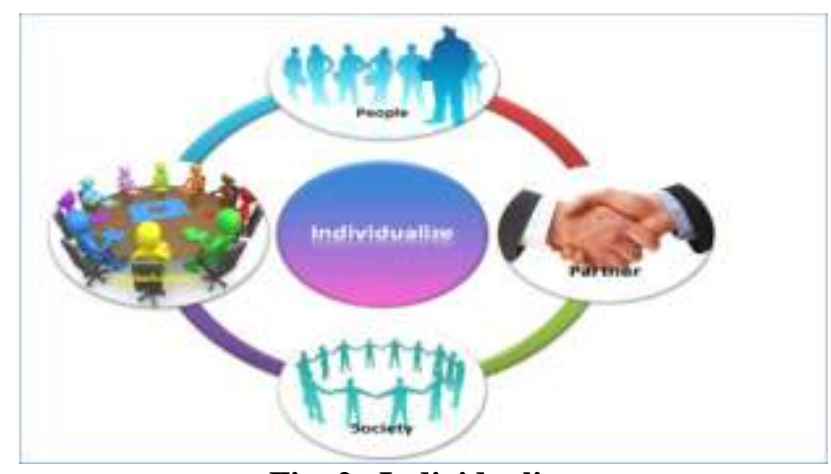

\subsection{Ignite}

Fig. 2 Individualize

The organizations which desire to have organizational excellence journey, need to first individualize everything what they do in terms of priorities, objectives, goals, strategy etc and also make all the different stakeholders to own it and accountable for everything that they do. Once it is achieved and the right system in put in place for individualization, it is the organizations responsibility to ignite various aspects in the organization so that individuals are excited to perform what they do. This can be achieved only when all the components in the Ignite phase are well addressed and streamlined for the smooth functioning of the organization. The key elements in the Ignite phase is shown below fig.3.

The Organization and its top management should ensure to provide the right systems, infrastructure, tools, processes, methodologies which are user friendly and can be easily usable so that all the relevant stakeholders i.e. individuals perform their activities seamlessly. The Organizations should continuously analyze on continuous basis and upgrade all the components in ignite phase so that benefit of latest technologies, tools and methodologies for the betterment of higher productivity and reduce the manual effort and also ignites the learning curve of the individuals. This is a major gap in most of the organizations that the top management will not give enough attention as long as things are getting done. As a matter of fact employees and relevant stakeholders will get frustrated as they keep doing the same activities and become like mechanical workers. Employees feel that it is a knowledge threat because of lack of learning opportunities. So it is highly desirable 
Individualize, Ignite, Inspire (I-I-I-model) The way to achieve organizational excellence.......

and inevitable to keep enhancing the various processes, methodologies, tools and systems so that every individuals feel that there is something new to learn and perform also because of new learning's, every individual gets charged up for higher performance. Though some of the best companies are doing this activities, still more than $80 \%$ of the companies are yet to take up this up gradation as a culture of the organization. Also, organizations should look in to the latest market trends and the requirements, should make the market to gear up the organizations capabilities and latest changes that happens in organizations. It is organizations responsibility to meet market and the end customers and ignite them with the relevant information so that their understanding on the changes in technology, processes and methodologies are well known to market and the customers.

Hence there is a need for holistic approach to ignite the individuals with continuous improvements in Systems, processes, methodologies, tools, techniques \& infrastructure. The best way to achieve this is to involve the individuals for all this up gradation and continues improvement activities so that again every individual feels the belongingness and ownership even in ignite phase. So both Individualize and Ignite phases should complement each other which means each one is within the other one.

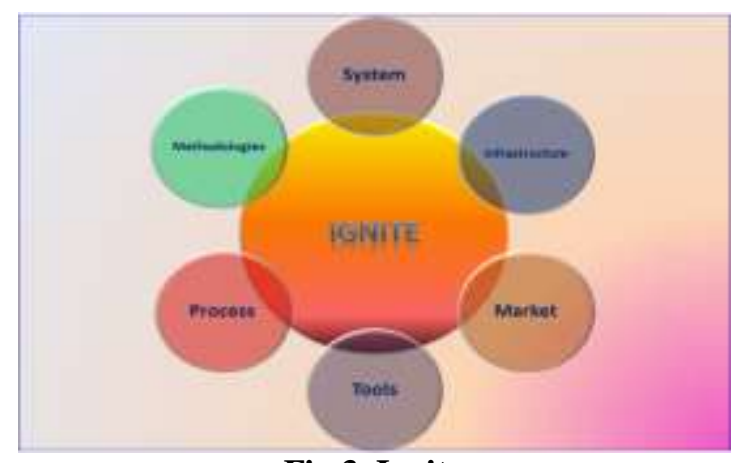

Fig 3. Ignite

\subsection{Inspire}

To Inspire is to exhibit visionary leadership and making every one in the organization to feel excited by his/her thoughts, actions and guidance. It also can be defined as making every one to aspire something from within. There are many inspiring leaders in the world like Jack Welch of General Electric in the global context and also Mr N.R Narayana Murthy of Infosys, Mr Ratan Tata of Tata Group etc. Every Organization builds on such visionaries' dreams or from their vision. But the fact of the day is that every individual is a leader by himself and everyone has a dream to do something big. But the issue that comes in the way is that every individual will not go forward to start an organization and which is not desired also. So the question is how do tap and utilize every one's ideas, visions and dreams in the organization to make the organization as a vibrant organization.

Today in most of the companies, the way that organizations works is that a leader (may be a chairman or CEO or the Board of the Directors) will have some charter in the mind and creates all the fundamental components like Vision, Mission, Strategy etc in the organization. Then down the line hundreds, thousands or sometimes lakhs of the employees will be working on the same. In many cases such a huge talented group of individuals will not get an opportunity for contributing to the overall vision formation of the organization. Hence most of the crowd ends up working on somebody's vision without owning it or without having passion in it. This is the key issue and also it is difficult issue to be addressed. In recent past few organizations are attempting to tackle this issue by encouraging the Innovation initiatives and also Dream a Dream ventures. Basically these initiatives will attract the employees those who are having different ideas of existing business or new business ideas which will make the organization grow $\mathrm{n}$-fold. Inspiration in the organization should not be limited at one level as is the case currently in most of the organizations. if it continues, the organizations will have a limited success stories or the success is limited by few ideas. So the culture of inspiration should be institutionalized and also channelized. Some of the ways of inspiring are as follows;

I. Every individual should be inspired within himself by doing something distinct .

II. Every Individual should have an opportunity for getting inspiration by learning something from others and it should be a continual process.

III. Every leader should be able provide inspiring leadership and lead by example.

IV. Inspiration is not something which is a closed affair within the organization, it should be continuous one by looking at different inspiring leaders within the similar industry or even outside of the industry. (ex: many CEO's and even Harward Business school members visited Mumbai Dabba wallas for learning the management skills and for their operational efficiency which greater than Six Sigma.) 


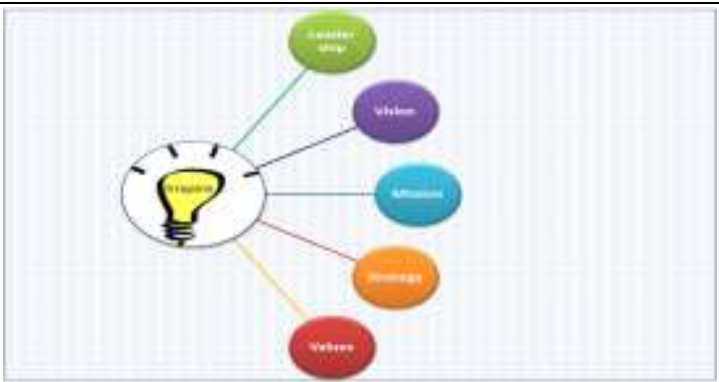

Fig.4 Inspire

\section{Conclusion}

Organizational Excellence is an endless journey and many of the organizations are striving to achieve Globally. Most of the countries are coming out with different models to help organization to achieve Organizational excellence ex: EFQM, Malcolm Baldridge Model ,Canadian model etc. Though adequate number of models are available and also the organizations are willing to achieve Business Excellence and Organization excellence, but still the desire results are far away. In this paper, all the efforts are put more on how to implement organizational excellence and what kind of strategy to adopt for bringing more focus for Organizational excellence. Also in this paper, suggested a different approach and a holistic model called III model (Individualize, Ignite and Inspire) which will definitely help organizations to make remarkable changes in their strategy for achieving Organizational excellence. The key essence of achieving organizational excellence in summary is shared vision, Ownership at every individual level ,accountability, belongingness .

\section{Acknowledgements}

\section{Author Biographies}

1. First Author : M. Madhusudhana Rao is a Software Quality professional having experience more than $22+$ yrs and associated with many reputed Indian \& global IT companies namely Wipro Technologies ,Sasken Communications and currently with Texas Instruments ,India. He has great deal of passion in Quality, Business Excellence, Six Sigma and helped many organizations for their continuous Quality improvement journey. Mr Rao is a certified Assessor for EFQM model and also Malcolm Baldridge model and was a part of the assessment Team for many large organizations through Confederation of Indian industry (CII).As a Six Sigma Master Black belt he has guided most critical Six Sigma projects and achieved breakthrough improvements and mentored many black belts to drive the Six Sigma projects. He is having wide experience in both service based organizations and also product based organizations . He is holding MS Quality Management from BITS Pilani, MBA (Operations Research \&International Business) and M.Sc. in Electronics by Qualifications.

2. Second Author: Dr.Sukumar Puhan is a professor in mechanical engineering department of GKM College of engineering, Chennai. He has more than five years of teaching experience and more than seven years of research experience. He exposed to advance research in renewable energy in India and Germany. He has obtained his master and doctorate from Anna University, Chennai. He has also obtained green belt in six sigma and certified Project Management Professional.

\section{References}

[1] Drucker, P. F., "Management: Tasks, Responsibilities, Practices". New York: Harper \& Row, 1973.

[2] Nadler, D.A., Gerstein, M.S., Shaw, R.B, "Organizational Architecture: Designs for Changing Organizations". San Francisco: Jossey-Bass, 1992.

[3] Page, D. (2000, July). Finding meaning through servant leadership in the workplace. Paper presented at the International Conference on Searching for Meaning in the New Millennium, Vancouver, BC, Canada.

[4] Page, D., \& Wong, P. T. P. (2000). A conceptual framework for measuring servant leadership.

[5] Gardner, H., Csikszentmihalyi, M., \& Damon, W. (2001). Good work: When excellence and ethics meet. New York, NY: Basic Books.

[6] Wong, P. T. P. (2002a). Creating a positive, meaningful work climate: A new challenge for management and leadership.

[7] Liker, J. K. (2004). The Toyota Way. New York, NY: McGraw-Hill.

[8] Crabtree, S. (2004a). The power of positive management (part 1). Gallup Management Journal. (http://gmi.gallup.com/content/default.asp?ci=13894)

[9] Crabtree, S. (2004b). The power of positive management (part 2). Gallup Management Journal. (http://gmi.gallup.com/content/default.asp?ci=14206)

[10] Wong, P. T. P. (2004). The paradox of servant leadership. Leadership Link, Spring, 2004, 3-5. Ohio State University, Leadership Research Center.

[11] Luthans, F., Luthans, K. W., \& Luthans, B. C. (2004). Positive psychological capital: Beyond human and social capital. Business horizons, 47, 45-50.

[12] Liker,J.K.\&Meier,D.P.(2007).Toyotatalent.NewYork,NY:McGraw-Hill. Linley, P. A., Harrington, S., \& Page, N. (in press). Handbook of positive psychology and work. New York, NY: Oxford University Press.

[13] Wong, P. T. P. (2007a). What makes a great worker? Retrieved on May 28, 2007 from http://meaning.ca/archives/presidents_columns/pres_col_mar_2007_great-worker.htm

[14] Wong, P. T. P. (2007b). What makes a great leader? LeadershipLink, 17, 1-6.

[15] Liker, J. K., \& Hoseus, M. (2008). Toyota culture: The heart and soul of the Toyota way. New York, NY: McGraw-Hill.

[16] Chao, D. K. (2009). Lean reflections: World's first lean coffee-table book. Vancouver, BC, Canada: Lean Sensei International. 